\title{
System Model Managing Complex Projects Based on Information Technologies
}

\author{
Gennady Kulikov \\ Ufa State Aviation Technical University \\ Ufa, Russia \\ gennadyg_98@yahool.com
}

\author{
Konstantin Rizvanov \\ Ufa State Aviation Technical University \\ Ufa, Russia \\ rizvanovk@bk.ru
}

\begin{abstract}
The principles of organizing the application of digital modeling based on the integration of 1D, 2D, 3D-4D methods are considered. 1D - as a mathematical simulation; 2D and 3D modeling, first of all, as design (geometric) modeling; 4D - as modeling of lifecycle centers themselves as attribute modeling (subject-oriented), allowing to generate mathematical, geometric and informational knowledge among specialists (in the field of editors, DBMS, Web, CAD/CAM/CAE/ERP/ MES/SCADA/ ... and others). The system requirements and the necessary professional competence of specialists for organizational and functional activity in the field of digital modeling of production processes are determined. The virtual model of a product that interacts with a real product at all gate system stages. Modern organizations are complex systems, information management of which is provided by a wide range of software. A large number of data sources make it difficult to consolidate data and obtain aggregated reports. Business process models are isomorphically mapped to the data accumulated during the operation of the information system, therefore, models can also be used to structure the data in the required context.
\end{abstract}

Keywords—system model, information technologies, digital modeling.

\section{INTRODUCTION}

The principles of systems engineering determine the presence of any system life cycle, which can be reflected in various aspects. In a narrow sense, we define the main stages of life cycle - the development and application of methods for digital modeling of production processes as systems [1-3].

Consider: 1D - as a mathematical simulation; 2D and 3D modeling, first of all, as design (geometric) modeling; 4D - as modeling of lifecycle centers themselves as attribute modeling (subject-oriented), allowing to generate mathematical, geometric and informational knowledge among specialists (in the field of editors, DBMS, Web, CAD/CAM/CAE/ERP/ MES/SCADA/ ... and others).

From the point of view of the necessary environment, this is, first of all, special software for 1D, 2D, 3D and 4D (Mathematics, Matlab, $\mathrm{CAD} / \mathrm{CAM}, \mathrm{PLM}$ ) modeling. This is a prerequisite for creating a unified information environment as a system.

Consider knowledge about the subject area as a set of digital models of production processes and their elements in 1D - 4D representations. We describe the main provisions of this set in the form of a generalized reference model that forms the set of necessary software for digital modeling.

Note that currently developed mathematical models and information systems, automating the technology of digital modeling and digital production. The first technologies were developed since 1998, when Neil Gershenfeld, a professor at the Massachusetts Institute of Technology, for the first time organized a course called "How to do almost everything" for students. In 2001, within the framework of a social program in the USA, the first laboratory FabLab was created by the MIT Bit and Atom Center. In addition to traditional equipment and technologies based on 1D - 2D views, it included milling machines for mechanical processing of materials, a 3D printer for printing plastic parts, a tool for creating printed circuit boards, a plotter for cutting vinyl, Arduino boards and other similar ones. means of production [1]. This, in fact, determined the path to the transition of the organization of digital production, that is, to digital modeling of production processes.

\section{RELATED WORK}

The main advantages of digital production for the domestic industry are:

- reducing the cost of technological preparation of production;

- reduction of areas of auxiliary production due to the fact that with the use of additive technologies, any part can be manufactured on a single machine;

- reducing the cost of repair and maintenance of equipment;

- reduction in the percentage of marriage in the enterprise.

But at the same time, in connection with the transition to the use of additive technologies, the question arises of training the personnel of an industrial enterprise so that it can perfectly master such technologies. 
An analysis of the application of additive technologies in digital production shows that the stage of the "Preparing Production" life cycle during the transition of the enterprise to these technologies is reduced by about 3-4 times [4].

Enterprise management is based on a comprehensive analysis of information reflecting compliance actual values characterizing the progress, status and effectiveness of their processes, routine or normative values. At the same analysis based evaluation of the effectiveness of the enterprise formed by management control actions on the production system. Therefore, becomes obvious how quickly and reliably the company's managers are provided with the necessary data on production processes, so effective management of industrial enterprise. One of the most effective tools to improve the management of production at the plant is the use of modern information technology capabilities.

Consider the basic principles of the situational centre in the organization of production planning at the level of the corporation:

- classification and structure the organizational and functional activities of the production system of the enterprise and the Corporation in accordance with the principles of system engineering (ISO/IEC 15288) and methodology of structuring information systems based on the Zachman Framework;

- the centralized management of projects based on Infor ERP LN (BAAN). Of particular importance ERP application systems acquires when creating engineering corporations or holdings. As a rule, the integration of several businesses in a production structure with internal cooperation, the problem arises to ensure coordinated activities within enterprises through complex production processes. Necessary to establish uniform rules for all businesses, core business processes governing manufacturing and financial planning, logistics, management and accounting accounting policies, methods of evaluating the performance of enterprises and the individual units, etc.;

- the centralized storage design data in PLM system Teamcenter for manage all the product information and related processes throughout its entire life cycle, from design and production to end of life;

- the provision of collective interaction on the basis of carrying out videoconferencing;

- the centralized solution of tasks of monitoring and control;

- the collection of information according to different criteria from different sources;

- the monitoring of the situation and providing the heads of aggregated and detailed information;

- the forecasting of situation development and selection of the best option control actions after assessing the reliability of forecasts, risks and other parameters. In recent years, began to increase the role of situational centers and contingency management, both in the world and in domestic practice. Great use they began to find decisionmaking for solving complex analytical problems, among which include management and production companies, holding companies and corporations;

- the planning, coordination and control over implementation of adopted decisions;

- the evaluation of the results of implementation.

Fig 1 shows the 0-th level Zachman matrix in terms of production planning [5].

\begin{tabular}{|c|c|c|c|}
\hline & Enterprise A & Enterprise B & Enterprise C \\
\hline Enterprise A & 1 & $\begin{array}{c}\text { Plan 1 } \\
\text { Unit 1 } \\
\text { Resource 1 }\end{array}$ & $\begin{array}{c}\text { Plan 2 } \\
\text { Unit 2 } \\
\text { Resource 2 }\end{array}$ \\
\hline Enterprise B & $\begin{array}{c}\text { Plan 1 } \\
\text { Unit 1 } \\
\text { Resource 1 }\end{array}$ & 1 & $\begin{array}{c}\text { Plan 3 } \\
\text { Unit 3 } \\
\text { Resource 3 }\end{array}$ \\
\hline Enterprise C & $\begin{array}{c}\text { Plan 2 } \\
\text { Unit 2 } \\
\text { Resource 2 }\end{array}$ & $\begin{array}{c}\text { Plan 3 } \\
\text { Unit 3 } \\
\text { Resource 3 }\end{array}$ & 1 \\
\hline
\end{tabular}

Fig 1. 0-th level Zachman matrix

Next level architecture shows the use of information systems in various models. Integration of design-technological space, management of resources and space in organizational management is provided with organizational and functional management and information systems ERP and PLM [4]. Table 1 shows the architecture of the information system of the situational centre for production planning.

Architecting models of design, manufacture and operation is described in [6-8].

\section{PROBLEM DEFINITION}

It is obvious that the key position in the organization and application of digital modeling, are specialists with relevant competencies. In modern conditions, enterprises, above all, annually increase the requirements for graduates of higher educational institutions, consisting in the formation of their competencies related to the issues of digital production. This is also determined by the fact that industrial enterprises began to move to a new level of development and equipment - new CNC machines began to appear, that is, the transition to digital production began, as well as the transition to the use of additive technologies.

To solve the described problem, it is proposed to implement the ITIL methodology, which allows building the tables of the RACI (responsible, approving, consulting, informed) and integrating into the existing processes for the coordination of digital documents. This will reduce the cost of licensed software, replacing it with viewers, for enterprise services that will be informed.

Let us describe the methodology of ITIL on the example of the corporate governance process, consisting of fourth parts: 
- description of the process with a brief outline of its objectives. It reveals the relationship between the process, information criteria, IT resources and management sections;

- description of the purpose of control for this process;

- description of incoming information and results of the process, table of RACI, goals and indicators;

- maturity model for this process.

The introduction of an effective methodology of corporate governance includes the definition of organizational structures, processes, positions and responsibilities.

The RACI table shows who is responsible, approving, consulting and informed.

Most of these systems offer the possibility of local search or analytics; however, for decision making it is necessary simultaneously use data from several systems, which can be a difficult task, because of incompatibility of systems or use of different data dictionaries.

Support for the product lifecycle (Fig. 1) is provided by a variety of different, often unrelated corporate information systems (CIS). For example, to automate engineering calculations and outline design using CAE-systems; for automation of designing and manufacturing of working design documentation CAD-systems; for automation of technological preparation of manufacture - CAM-systems; for the management of product data and its configurations PDM-systems; for the automation of production planning and management of the processes of manufacturing products, stocks, production resources, transport, etc. - ERP BaaN system.

Fig. 2 shows the Product Life Cycle Information Support System in the UEIA, based on the CALS methodology.

Classification can be performed using information retrieval systems. In this case, the search index will play the role of the classifier.

When referring to the query to the classifier, it is possible to extract pointers to information resources from different systems uniformly.

Fig. 3 shows the relationship between the organization's business processes and the content of the information space.
Table 1. Architecture of the information system

\begin{tabular}{|c|c|c|c|c|c|c|c|}
\hline & $\mathbf{O M}$ & $\begin{array}{c}\text { DT } \\
\mathbf{M}\end{array}$ & $\mathbf{L M}$ & $\mathbf{P M}$ & EM & $\begin{array}{c}\text { Op } \\
\mathbf{M}\end{array}$ & IM \\
\hline 1 & 1 & $\begin{array}{c}\text { PD } \\
M\end{array}$ & $\begin{array}{l}\mathrm{SC} \\
\mathrm{M}\end{array}$ & $\begin{array}{c}\text { MR } \\
P\end{array}$ & ERP & $\begin{array}{l}\text { PL } \\
\text { M }\end{array}$ & $\begin{array}{l}\text { BP } \\
\text { M }\end{array}$ \\
\hline 2 & $\begin{array}{c}\mathrm{RD} \\
\mathrm{M}\end{array}$ & 1 & $\begin{array}{l}\mathrm{PD} \\
\mathrm{M} / \\
\mathrm{SC} \\
\mathrm{M}\end{array}$ & $\begin{array}{c}\mathrm{PD} \\
\mathrm{M} / \\
\mathrm{MR} \\
\mathrm{P}\end{array}$ & $\begin{array}{c}\text { PD } \\
\text { M/ } \\
\text { ERP }\end{array}$ & $\begin{array}{l}\mathrm{PD} \\
\mathrm{M} / \\
\mathrm{PL} \\
\mathrm{M}\end{array}$ & $\begin{array}{l}\mathrm{PD} \\
\mathrm{M} / \\
\mathrm{BP} \\
\mathrm{M}\end{array}$ \\
\hline 3 & $\begin{array}{c}\mathrm{SC} \\
\mathrm{M}\end{array}$ & $\begin{array}{c}\mathrm{SC} \\
\mathrm{M} / \\
\mathrm{PD} \\
\mathrm{M}\end{array}$ & 1 & $\begin{array}{c}\mathrm{SC} \\
\mathrm{M} / \\
\mathrm{MR} \\
\mathrm{P}\end{array}$ & $\begin{array}{c}\mathrm{SC} \\
\mathrm{M} / \\
\mathrm{ERP}\end{array}$ & $\begin{array}{l}\mathrm{SC} \\
\mathrm{M} / \\
\mathrm{PL} \\
\mathrm{M}\end{array}$ & $\begin{array}{l}\mathrm{SC} \\
\mathrm{M} / \\
\mathrm{BP} \\
\mathrm{M}\end{array}$ \\
\hline 4 & $\begin{array}{c}\text { MR } \\
\mathrm{P}\end{array}$ & $\begin{array}{c}\text { MR } \\
\mathrm{P} / \\
\mathrm{PD} \\
\mathrm{M}\end{array}$ & $\begin{array}{c}\text { MR } \\
\mathrm{P} / \\
\mathrm{SC} \\
\mathrm{M}\end{array}$ & 1 & $\begin{array}{c}\text { MR } \\
\text { P/ } \\
\text { ERP }\end{array}$ & $\begin{array}{c}\text { MR } \\
\mathrm{P} / \\
\mathrm{PL} \\
\mathrm{M}\end{array}$ & $\begin{array}{c}\text { MR } \\
\mathrm{P} / \\
\mathrm{BP} \\
\mathrm{M}\end{array}$ \\
\hline 5 & ERP & $\begin{array}{c}\text { ERP } \\
/ \\
\text { PD } \\
M\end{array}$ & $\begin{array}{c}\text { ERP } \\
/ \\
\text { SC } \\
\mathrm{M}\end{array}$ & $\begin{array}{c}\text { ERP } \\
/ \\
\text { MR } \\
\mathrm{P}\end{array}$ & 1 & $\begin{array}{c}\text { ERP } \\
/ \\
\text { PL } \\
\text { M }\end{array}$ & $\begin{array}{c}\text { ERP } \\
/ \\
\text { BP } \\
\text { M }\end{array}$ \\
\hline 6 & $\begin{array}{l}\text { PL } \\
\text { M }\end{array}$ & $\begin{array}{c}\mathrm{PL} \\
\mathrm{M} / \\
\mathrm{PD} \\
\mathrm{M}\end{array}$ & $\begin{array}{l}\mathrm{PL} \\
\mathrm{M} / \\
\mathrm{SC} \\
\mathrm{M}\end{array}$ & $\begin{array}{c}\mathrm{PL} \\
\mathrm{M} / \\
\mathrm{MR} \\
\mathrm{P}\end{array}$ & $\begin{array}{c}\text { PL } \\
\text { M/ } \\
\text { ERP }\end{array}$ & 1 & $\begin{array}{l}\mathrm{PL} \\
\mathrm{M} / \\
\mathrm{BP} \\
\mathrm{M}\end{array}$ \\
\hline 7 & $\begin{array}{l}\mathrm{BP} \\
\mathrm{M}\end{array}$ & $\begin{array}{c}\mathrm{BP} \\
\mathrm{M} / \\
\mathrm{PD} \\
\mathrm{M}\end{array}$ & $\begin{array}{l}\mathrm{BP} \\
\mathrm{M} / \\
\mathrm{SC} \\
\mathrm{M}\end{array}$ & $\begin{array}{c}\mathrm{BP} \\
\mathrm{M} / \\
\mathrm{MR} \\
\mathrm{P}\end{array}$ & $\begin{array}{c}\text { BP } \\
\text { M/ } \\
\text { ERP }\end{array}$ & $\begin{array}{l}\mathrm{BP} \\
\mathrm{M} / \\
\mathrm{PL} \\
\mathrm{M}\end{array}$ & 1 \\
\hline
\end{tabular}

where 1 - Organizational model (OM);

2 - Design and technological model (DTM);

3 - Logistical model (LM);

4 - Production model (PM);

5 - Economical model (EM);

6 - Operational model (OpM);

7 - Information model (IM). 


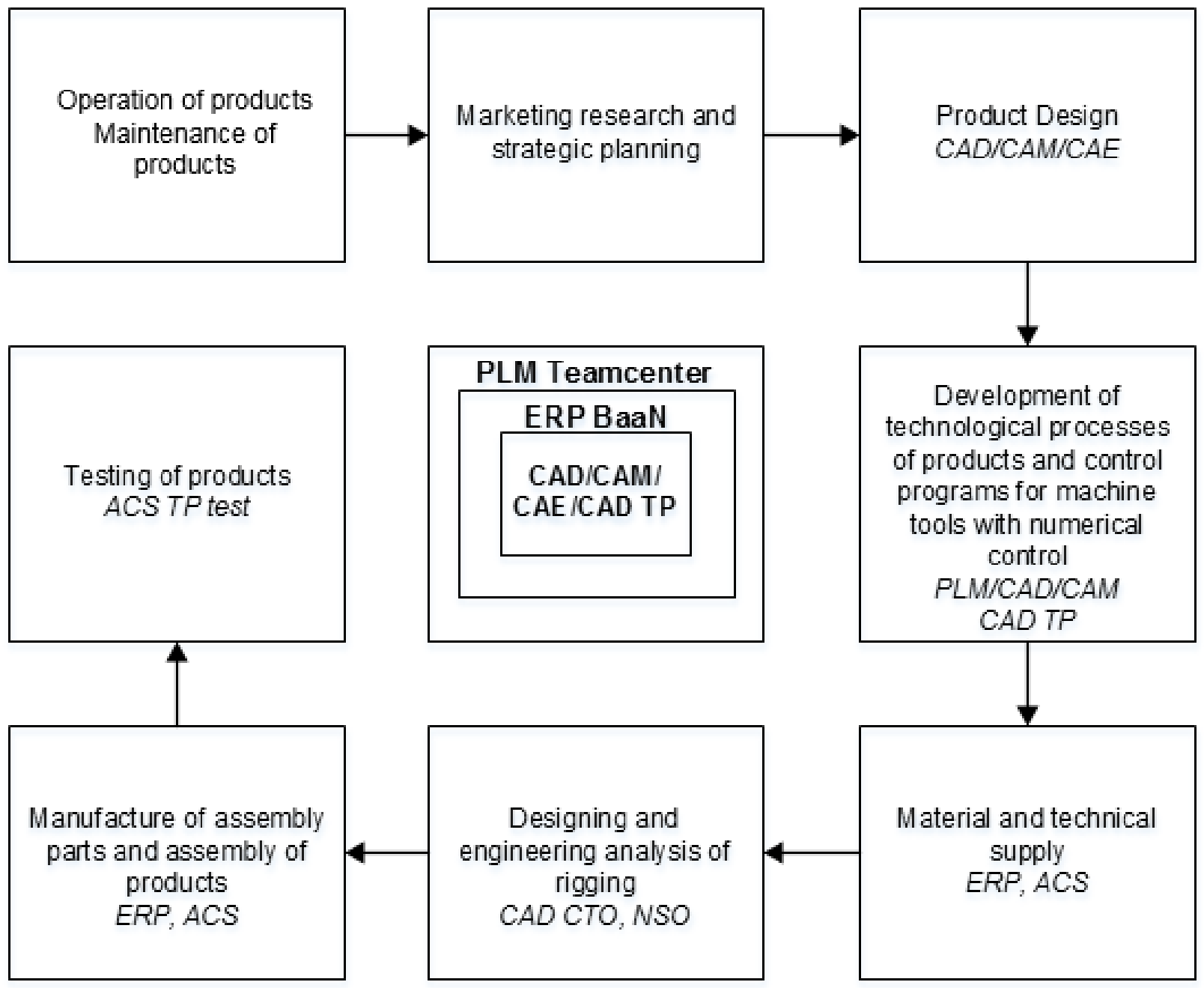

Fig. 2. Scheme of information support of product life cycle on the basis of CALS methodology

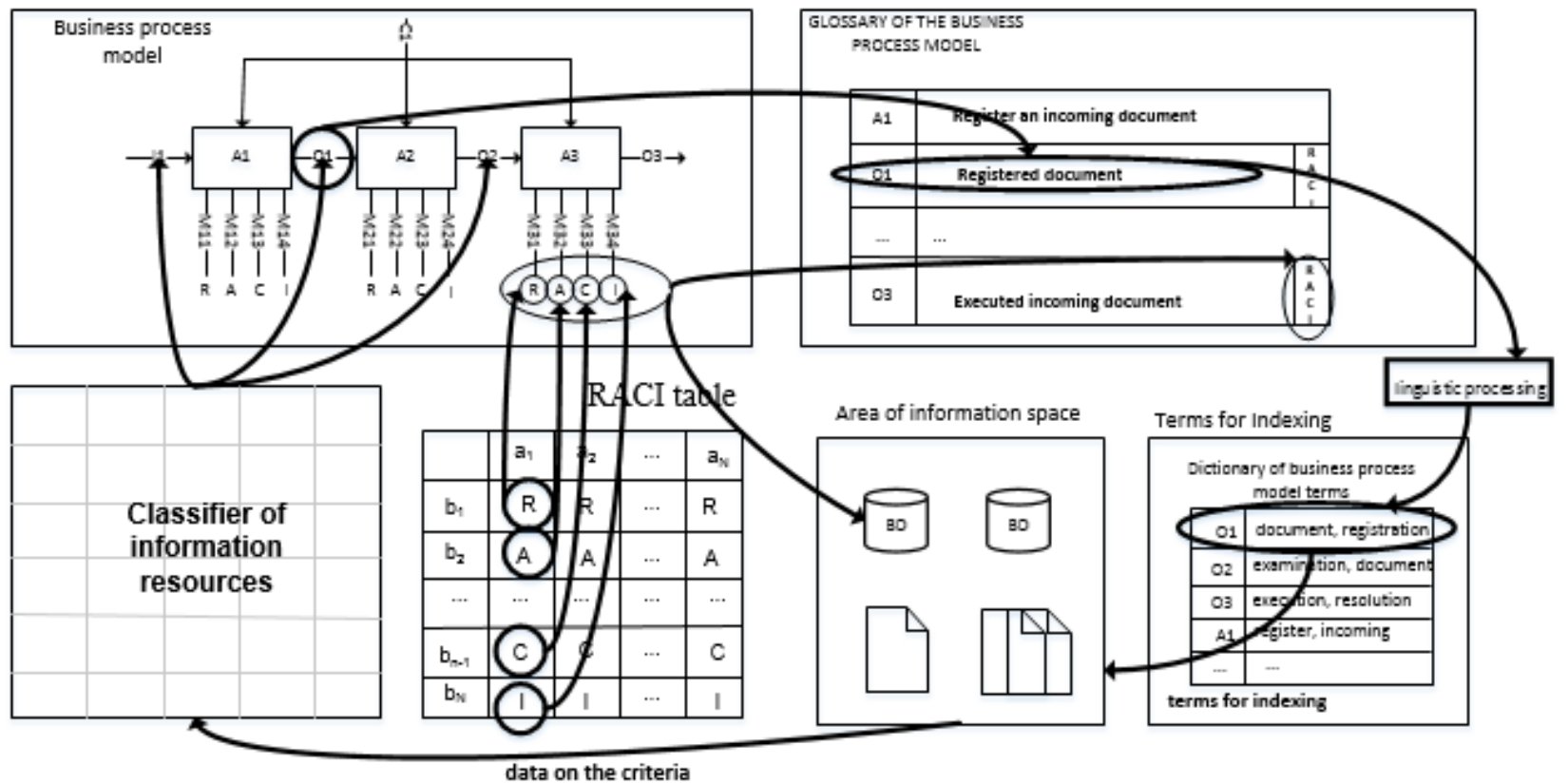

Fig. 3. The relationship between the organization's business processes and the content of the information space 


\section{MATHEMATICAL MODEL}

Let us describe the relationship between the business process model and the content of the information space using the apparatus of the mathematical theory of categories. For each pair of objects A, Bis the set of morphisms $\operatorname{Hom}_{\mathrm{C}}(\mathrm{A}, \mathrm{B})$, and to each morphism there correspond unique $\mathrm{A}$ and $\mathrm{B}$.

For each pair of morphisms $f \circ \operatorname{Hom}_{C}(A, B)$ and $g \circ \operatorname{Hom}_{C}(B, C)$ is the composition $f \circ g=\operatorname{Hom}_{C}(A, C)$.

For each object $\mathrm{A}$ is the identity morphism $i d_{A} \in \operatorname{Hom}(A, A)$, at which two axioms are satisfied:

- the composition operation is associative: $f \circ(g \circ h)=(f \circ g) \circ h$,

- the identity morphism acts trivially: $f \circ i d_{A}=i d_{B} \circ g$.

Establishment of relations between data is possible due to the fact that the system model satisfies the requirements of the mathematical theory of categories, i.e. there is a class of objects, a class of morphisms, the composition operation is associative, the identity morphism acts trivially.

Let us illustrate this on the functional, information and dynamic models.

Fig. 4 shows the processes and data in the form of a category, where on the functional model:

- class of objects $-\mathrm{Obj}_{\mathrm{C}}$ - inputs / outputs of the business process $\left(\mathrm{A}_{1}, \mathrm{~A}_{2}, \ldots, \mathrm{A}_{\mathrm{n}}\right)$;

- $\quad$ class of morphisms - Homc $\left(\mathrm{A}_{\mathrm{i}}, \mathrm{A}_{\mathrm{j}}\right)$ - functions of the business process;

- the composition operation is associative due to decomposition.

On the information model:

- class of objects $-\mathrm{Obj}_{\mathrm{C}}-$ the essence of the information model;

- $\quad$ class of morphisms - $\operatorname{Hom}_{\mathrm{C}}\left(\mathrm{A}_{\mathrm{i}}, \mathrm{A}_{\mathrm{j}}\right)$-relations between entities;

- the composition operation is associative due to categorization.

On a dynamic model:

- $\quad$ class of objects - ObjC - tasks of the dynamic model;
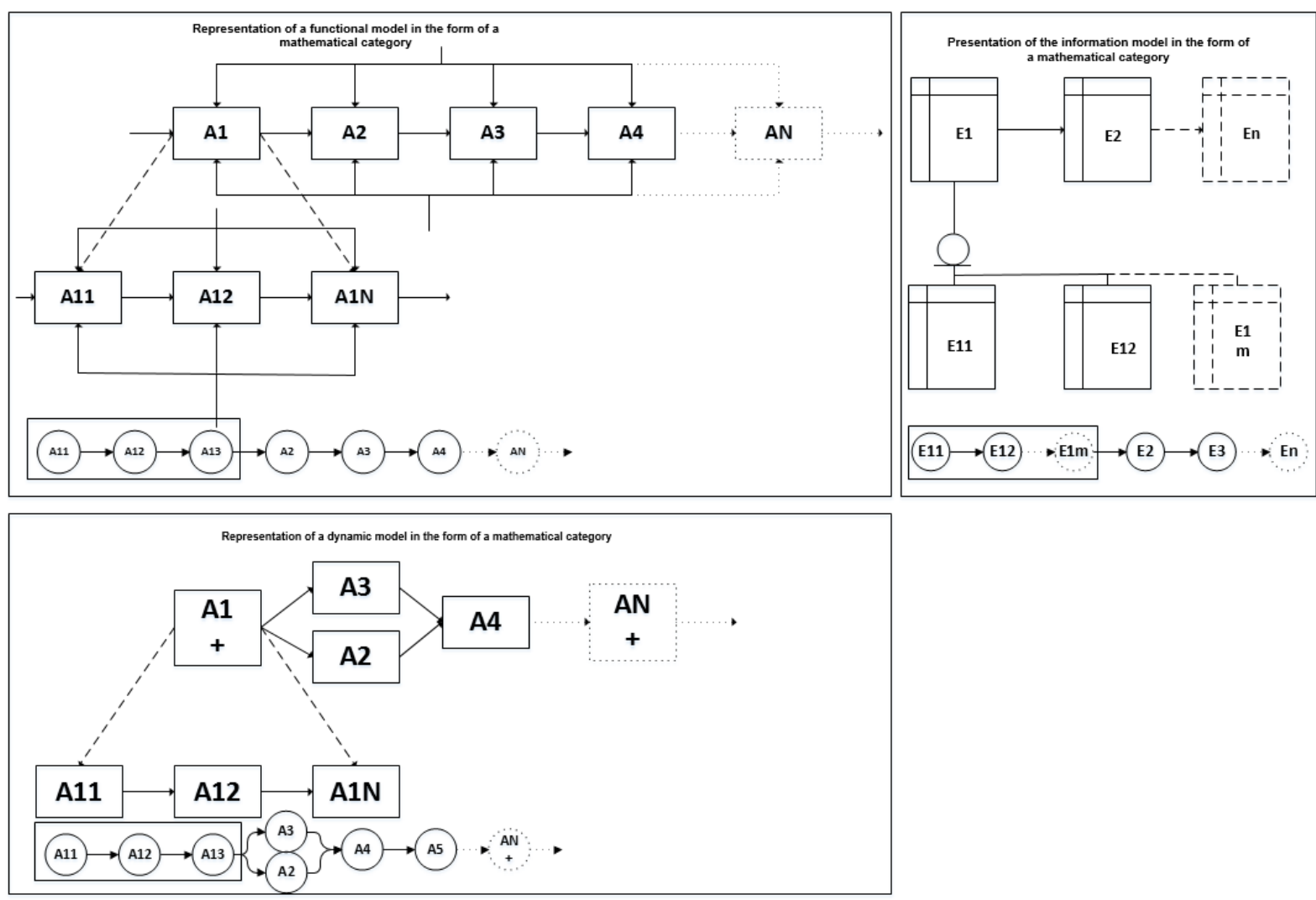

Fig. 4. Representing processes and data in the form of categories 
- class of morphisms - Homc (Ai,Aj) transitions between tasks;

- the composition operation is associative due to partitioning into subsystems.

\section{REFERENCES}

[1] G. G. Kulikov, V. N. Kruzhkov, E. A. Dron, A. A. Kolesnikov, O. N. Kruzhkov, A. M. Sharipova, K. A. Rizvanov Introduction to the information systems of digital modeling: a manual / Ufimsk. state. aviats. tech. un-t. Ufa: RIC UGATU, 2017. - 140 p.

[2] G.G. Kulikov, G.G. Pogorelov, Yu. O. Bagaeva Information support system for the operation of electronic aggregates GTE // Bulletin USATU, 2010. - T. 14. - № 3. P. 32-41.

[3] K.A. Rizvanov, N.O. Nikulina Building a common information space using the example of INFOR ERP LN for project management // Mater. V Vseros. scientifictechn. Conf., Ufa: OAO UMPO, 2011. P.290-293.

[4] G.G. Kulikov, K.A. Rizvanov, V.L. Khristolyubov Organization of a common information space for distributed execution of projects in the aircraft engine industry / / Vestnik USATU: Nauk. journal. Ufa. state. aviats. tech. un-ta. Ser. Management in social and economic systems, vol.16, № 6 (51) / 2012. - p.202-210.

[5] G.G. Kulikov, K.A. Rizvanov, S.S. Denisova The architecture of the integrated information model for the development, production and operation of GTE in conjunction with its automatic control, monitoring and diagnostic system / ISSN 1998-6629. Bulletin of the Samara State Aerospace University No. 3 (19) Part 1. 2009, p. 244-252.

[6] A.V. Rechkalov, A.V. Artyukhov, K.A. Rizvanov The concept of the structural and information organization of the situational center for the operational management of the machine-building division with territorially distributed production // Vestnik UMO. Economics, statistics and informatics. MESI, No. 3, 2014. P. 192-195.

[7] M.B. Guzairov, G.G. Kulikov, K.A. Rizvanov Structural model of the information system for industrial planning // CSIT'2014, v. 1/2014, Sheffield, England. - P. 10-14.

[8] G.G. Kulikov, K.A. Rizvanov Organization of planning system of machine-building corporation on the basis of system model of virtual production // Scientific horizons 2015 Materials of the XI International scientific and practical conference. 2015. P. 69-74. 